Pacific Journal of Mathematics

A REMARK ON INFINITELY NUCLEARLY DIFFERENTIABLE 


\section{A REMARK ON INFINITELY NUCLEARLY DIFFERENTIABLE FUNCTIONS}

\section{TEÓFIlo ABUABara}

There is an infinitely nuclearly differentiable function of bounded type from $E$ to $R$ which is not of bounded-compact type, when $E=l_{1}$, the Banach space of all summable sequences of real numbers.

Let $E$ and $F$ be two real Banach spaces. A mapping $f: E \rightarrow F$ is said to be weakly uniformly continuous on bounded subsets of $E$ if for each bounded set $B \subset E$ and each $\varepsilon>0$, there are $\phi_{1}, \phi_{2}, \cdots$, $\phi_{k} \in E^{\prime}$ and $\delta>0$ such that if $x, y \in B,\left|\phi_{i}(x)-\phi_{i}(y)\right|<\delta(i=1,2, \cdots, k)$, then $\|f(x)-f(y)\|<\varepsilon . \quad C_{w}^{m}(E ; F)$ is the space of $m$-times continuously differentiable mappings $f: E \rightarrow F$ satisfying the following conditions:

(1) $\hat{d}^{j} f(x) \in \mathscr{P}_{w}\left({ }^{j} E ; F\right)(x \in E, j \leqq m)$

(2) $\hat{d}^{j} f: E \rightarrow \mathscr{\mathscr { P }}_{w}\left({ }^{j} E ; F\right)$ is weakly uniformly continuous on bounded subsets of $E$, where $\mathscr{P}_{w}\left({ }^{m} E ; F\right)(m \in N)$ is the Banach space of continuous $m$-homogeneous polynomials which are weakly uniformly continuous on bounded subsets of $E$, its norm being the one induced on it by the current norm of $\mathscr{P}\left({ }^{m} E ; F\right)$. Set

$$
C_{w}^{\infty}(E ; F)=\bigcap_{m=0}^{+\infty} C_{w}^{m}(E ; F) .
$$

$C_{w}^{m}(E ; F)$ is endowed with the topology $\tau_{b}^{m}$ generated by the following system of semi-norms

$$
f \in C_{w}^{m}(E ; F) \sup \left\{\left\|\hat{d}^{j} f(x)\right\| ; x \in B, j \leqq m\right\},
$$

where $B$ runs through the bounded subsets of $E$.

For further details we refer to Aron-Prolla [1].

Proposition 1 (Aron-Prolla [1]). If $E^{\prime}$ has the bounded approximation property, then $\mathscr{P}_{f}(E ; F)$ is $\tau_{b}^{m}$-dense in $C_{w}^{m}(E ; F)$, for all $m \geqq 1$.

Hence, since $\|P\| \leqq\|P\|_{N}$ for every $P \in \mathscr{P}_{N}\left({ }^{m} E ; F\right)(m \in N)$, then $\mathscr{E}_{N b c}(E ; F)$ is contained in $C_{w}^{\infty}(E ; F)$.

Proposition 2 (Aron-Prolla [1]). Let $f: E \rightarrow F$ be a weakly uniformly continuous mapping on bounded sets. If $B \subset E$ is a bounded set, then $f(B)$ is precompact.

Proposition 3. $\mathscr{E}_{N b c}\left(l_{1}\right) \neq \mathscr{E}_{N b}\left(l_{1}\right)$, that is, there is an infinitely 
nuclearly differentiable function of bounded type from $l_{1}$ to $R$ which is not of bounded-compact type.

Proof. Set

$$
g: \boldsymbol{R} \longrightarrow \boldsymbol{R} \quad t \longmapsto g(t)= \begin{cases}e^{-1 / t} & t>0 \\ 0 & t \leqq 0\end{cases}
$$

Let us define

$$
f: l_{1} \longrightarrow \boldsymbol{R}\left(x_{n}\right)_{n} \longrightarrow f\left(\left(x_{n}\right)_{n}\right)=\sum_{n=1}^{+\infty} g\left(x_{n}\right) .
$$

Then $f$ is an infinitely nuclearly differentiable function of bounded type, but it is not of bounded-compact type. Indeed,

(a) $f \in \mathscr{E}_{N b}\left(l_{1}\right)$. (i) $f$ is bounded on bounded subsets of $l_{1}$. More precisely, there is $\varepsilon>0$ such that if $x \in l_{1},\|x\|_{1} \leqq R$, then $|f(x)| \leqq$ $R(1+1 / \varepsilon)$. Indeed, since $\lim _{t \rightarrow 0} 1 / t \cdot g(t)=0$, there is $\varepsilon>0$ such that if $|t|<\varepsilon$, then $g(t)<|t|$. Now, if $\|x\|_{1} \leqq R$, then we get that card $\left(\left\{n ;\left|x_{n}\right| \geqq \varepsilon\right\}\right) \leqq R / \varepsilon$. Therefore, if $\|x\|_{1} \leqq R$, we have that

$$
|f(x)|=\sum_{n=1}^{+\infty} g\left(x_{n}\right)=\sum_{x_{n} \geqq \varepsilon} e^{-1 / x_{n}}+\sum_{\left|x_{n}\right|<\varepsilon} g\left(x_{n}\right) \leqq R / \varepsilon+\|x\|_{1} \leqq R(1+1 / \varepsilon) .
$$

Hence $f$ is bounded of bounded sets.

(ii) $f \in C^{\infty}\left(l_{1}\right)$. Indeed, for every fixed $x=\left(x_{n}\right)_{n} \in l_{1}$, let $K=$ $\overline{\left\{x_{n}\right\}_{n}} \subset \boldsymbol{R}$ and let

$$
L_{k}(x)=\sum_{n=1}^{+\infty} g^{(k)}\left(x_{n}\right) \overbrace{e_{n} \times e_{n} \times \cdots \times e_{n}}^{k \text {-times }},
$$

$n$th

for $k=1,2, \cdots$, where $e_{n}=(0,0, \cdots, 0,1,0, \cdots)$. Notice that $L_{k}(x) \in \mathscr{L}\left({ }^{k} l_{1}\right)$, since if $M=\sup _{n}\left|g^{(k)}\left(x_{n}\right)\right|$, then $\left\|L_{k}(x)\left(h_{1}, h_{2}, \cdots, h_{k}\right)\right\| \leqq$ $M\left\|h_{1}\right\|_{1}\left\|h_{2}\right\|_{1} \cdots\left\|h_{k}\right\|_{1}$. Let us show that $d^{k} f(x)$ exists and $d^{k} f(x)=$ $L_{k}(x)$ for $k=1,2, \cdots$, using induction on $k$. Indeed, for $k=1$, since $g$ is uniformly differentiable on compact sets, given $\varepsilon>0$ there is $\delta>0$ such that

$$
|v|<\delta \Longrightarrow\left|g(t+v)-g(t)-g^{\prime}(t) v\right|<\varepsilon|v|,
$$

for every $t \in K$. Therefore,

$$
h \in l_{1},\|h\|_{1}<\delta \Longrightarrow\left|f(x+h)-f(x)-L_{1}(x) h\right|<\varepsilon\|h\|_{1} .
$$

It follows that $d f(x)=L_{1}(x)$. Let us assume that $d^{k} f(x)=L_{k}(x)$. Then, 


$$
\begin{aligned}
& \left\|d^{k} f(x+h)-d^{k} f(x)-L_{k+1}(x) h\right\| \\
& \quad=\left\|\sum_{n=1}^{+\infty}\left(g^{(k)}\left(x_{n}+h_{n}\right)-g^{(k)}\left(x_{n}\right)-g^{(k+1)}\left(x_{n}\right) h_{n}\right) \cdot e_{n} \times e_{n} \times \cdots \times e_{n}\right\| \\
& \quad=\sum_{n=1}^{+\infty}\left|g^{(k)}\left(x_{n}+h_{n}\right)-g^{(k)}\left(x_{n}\right)-g^{(k+1)}\left(x_{n}\right) h_{n}\right| .
\end{aligned}
$$

Now, since $g^{(k)}$ is uniformly differentiable on compact sets, given $\varepsilon>0$, there is $\delta>0$ such that

$$
|v|<\delta \Longrightarrow\left|g^{(k)}(t+v)-g^{(k)}(t)-g^{(k+1)}(t) v\right|<\varepsilon|v|,
$$

for every $t \in K$. Thus,

$$
h \in l_{1},\|h\|_{1}<\delta \Longrightarrow\left\|d^{k} f(x+h)-d^{k} f(x)-L_{k+1}(x) h\right\|<\varepsilon\|h\|_{1} .
$$

Hence, $d^{k+1} f(x)=L_{k+1}(x)$. It follows that $f \in C^{\infty}\left(l_{1}\right)$.

(iii) $\left.\hat{d}^{k} f(x)=\sum_{n=1}^{+\infty} g^{(k)}\left(x_{n}\right) \cdot e_{n}^{k} \in \mathscr{P}_{N}{ }^{k} l_{1}\right)$.

Moreover, $\hat{d}^{k} f: l_{1} \rightarrow \mathscr{P}_{N}\left({ }^{k} l_{1}\right)$ is bounded on bounded sets. Indeed, since $\lim _{t \rightarrow 0} 1 / t \cdot g^{(k)}(t)=0$, there is $\varepsilon>0$ such that if $|t|<\varepsilon$, then $\left|g^{(k)}(t)\right|<|t|$. Now, if $x \in l_{1},\|x\|_{1} \leqq R$, then card $\left(\left\{n ;\left|x_{n}\right| \geqq \varepsilon\right\}\right) \leqq R / \varepsilon$. Therefore, if $\|x\|_{1} \leqq R$, we have that

$$
\begin{aligned}
\left\|\hat{d}^{k} f(x)\right\|_{N} & \leqq \sum_{n=1}^{+\infty}\left|g^{(k)}\left(x_{n}\right)\right| \\
& =\sum_{x_{n} \geqq \varepsilon}\left|P\left(1 / x_{n}\right)\right| e^{-1 / x_{n}}+\sum_{\left|x_{n}\right|<\varepsilon} g^{(k)}\left(x_{n}\right) \\
& \leqq|P|(1 / \varepsilon) \cdot R / \varepsilon+\|x\|_{1} \\
& \leqq R(1+|P|(1 / \varepsilon) / \varepsilon),
\end{aligned}
$$

where if $P=\Sigma a_{n} z^{n}$, then $|P|=\Sigma\left|a_{n}\right| z^{n}$. Hence the assertion follows.

(iv) The mapping $\hat{d}^{k} f: l_{1} \rightarrow \mathscr{P}_{N}\left({ }^{k} l_{1}\right)$ is differentiable of first order when $\mathscr{P}_{N}\left({ }^{k} l_{1}\right)$ is endowed with its nuclear norm. Indeed, set

$$
T_{k}(x)=\sum_{n=1}^{+\infty}\left(g^{(k+1)}\left(x_{n}\right) \cdot e_{n}\right) \cdot e_{n}^{k} \in \mathscr{L}\left(l_{1} ; \mathscr{P}_{N}\left({ }^{k} l_{1}\right)\right),
$$

for $k=0,1,2, \cdots$. Then

$$
\begin{aligned}
& \left\|\hat{d}^{k} f(x+h)-\hat{d}^{k} f(x)-T_{k}(x) h\right\|_{N} \\
& \quad=\left\|\sum_{n=1}^{+\infty}\left(g^{(k)}\left(x_{n}+h_{n}\right)-g^{(k)}\left(x_{n}\right)-g^{(k+1)}\left(x_{n}\right) h_{n}\right) \cdot e_{n}^{k}\right\|_{N} \\
& \quad \leqq \sum_{n=1}^{+\infty}\left|g^{(k)}\left(x_{n}+h_{n}\right)-g^{(k)}\left(x_{n}\right)-g^{(k+1)}\left(x_{n}\right) h_{n}\right| .
\end{aligned}
$$

As in (iii), given $\varepsilon>0$, there is $\delta>0$ such that

$$
h \in l_{1},\|h\|_{1}<\delta \Longrightarrow\left\|\hat{d}^{k} f(x+h)-\hat{d}^{k} f(x)-T_{k}(x) h\right\|_{N}<\varepsilon\|h\|_{1} .
$$

Hence, $d\left(d^{k} f\right)(x)=T_{k}(x)$, when $\mathscr{P}_{N}\left({ }^{k} l_{1}\right)$ is endowed with the nuclear norm. Moreover, the mapping $T_{k}: l_{1} \rightarrow \mathscr{C}\left(l_{1} ; \mathscr{P}_{N}\left({ }^{k} l_{1}\right)\right)$ is continuous, 
for $k=0,1,2, \cdots$. Indeed,

$$
T_{k}(x+h)-T_{k}(x)=\sum_{n=1}^{+\infty}\left[\left(g^{(k+1)}\left(x_{n}+h_{n}\right)-g^{(k+1)}\left(x_{n}\right)\right) \cdot e_{n}\right] \cdot e_{n}^{k} .
$$

Therefore,

$$
\begin{aligned}
\left\|T_{k}(x+h)-T_{k}(x)\right\| & =\sup _{\|w\|_{1} \leq 1}\left\|\sum_{n=1}^{+\infty}\left(g^{(k+1)}\left(x_{n}+h_{n}\right)-g^{(k+1)}\left(x_{n}\right)\right) w_{n} \cdot e_{n}^{k}\right\|_{N} \\
& \leqq \sup _{\|w\|_{1} \leqq 1} \sum_{n=1}^{+\infty}\left|g^{(k+1)}\left(x_{n}+h_{n}\right)-g^{(k+1)}\left(x_{n}\right) \| w_{n}\right| \\
& =\sum_{n=1}^{+\infty}\left|g^{(k+1)}\left(x_{n}+h_{n}\right)-g^{(k+1)}\left(x_{n}\right)\right| \\
& =\sum_{n=1}^{+\infty}\left|g^{(k+2)}\left(\theta_{n}\right)\right|\left|h_{n}\right|,
\end{aligned}
$$

where $\theta_{n} \in\left(x_{n}, x_{n}+h_{n}\right)$. Set $\alpha=\sup _{y \in\left[0, \max _{n}\left|x_{n}\right|+1\right]}\left|g^{(k+2)}(y)\right|$. Given $\varepsilon>0$, set $\delta=\min \{\varepsilon / \alpha, 1\}$. Then,

$$
h \in l_{1},\|h\|_{1}<\delta \Longrightarrow\left\|T_{k}(x+h)-T_{k}(x)\right\|<\varepsilon .
$$

It follows that $T_{k}$ is continuous. Thus, $T_{k}$ is differentiable of first order.

(i)-(iv) imply $f \in \mathscr{E}_{N b}\left(l_{1}\right)$.

(b) $f \notin \mathscr{C}_{N b c}\left(l_{1}\right)$. Indeed, $d f\left(e_{n}\right)=e^{-1} \cdot e_{n}$. Therefore, $d f\left(B_{1}\right)$ is not a precompact subset of $l_{1}^{\prime}$, where $B_{1}$ is the unit ball of $l_{1}$. Hence the assertion follows of Propositions 1 and 2 above.

Hence Proposition 3 follows.

I thank Richard Aron for valuable conversations.

\section{REFERENCES}

1. R. Aron and J. Prolla, Polynomial approximation of differentiable functions on Banach spaces, to appear.

2. L. Nachbin and S. Dinee, Entire functions of exponential type bounded on the real axis and Fourier transform of distributions with bounded supports, Israel J. Math., 13 (1972), 321-326.

3. L. Nachbin, Topology on spaces of holomorphic mappings, Springer-Verlag, Ergebnisse der Mathematik, 471969.

Received February 24, 1978.

Instituto de Matemática Pura E Aplicada

RUA LUIZ DE CAMÕES 68

Rio DE JANEIRO, ZC-58, BRAZIL 


\section{PACIFIC JOURNAL OF MATHEMATICS}

EDITORS

RICHARD ARENS (Managing Editor)

University of California

Los Angeles, California 90024

C. W. Curtis

University of Oregon

Eugene, OR 97403

C. C. MOORE

University of California

Berkeley, CA 94720
J. DUGUNDJI

Department of Mathematics University of Southern Californı Los Angeles, California 90007

R. Finn and J. Milgram Stanford University Stanford, California 94305

\section{ASSOCIATE EDITORS}

E. F. BECKENBACH

B. H. NEUMANN

F. WOLF

K. YoSHIDA

\section{SUPPORTING INSTITUTIONS}

UNIVERSITY OF BRITISH COLUMBIA
CALIFORNIA INSTITUTE OF TECHNOLOGY
UNIVERSITY OF CALIFORNIA
MONTANA STATE UNIVERSITY
UNIVERSITY OF NEVADA, RENO
NEW MEXICO STATE UNIVERSITY
OREGON STATE UNIVERSITY
UNIVERSITY OF OREGON

UNIVERSITY OF SOUTHERNEALIFORNIA STANFORD UNIVERSITY UNIVERSITY OF HAWAII UNIVERSITY OF TOKYO UNIVERSITY OF UTAH WASHINGTON STATE UNIVERSITY UNIVERSITY OF WASHINGTON 


\section{Pacific Journal of Mathematics \\ Vol. 79 , No. 1 \\ May, 1978}

Teófilo Abuabara, A remark on infinitely nuclearly differentiable

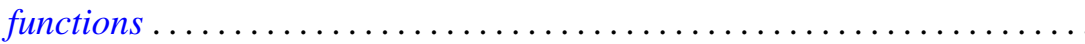

David Fenimore Anderson, Projective modules over subrings of $k[X, Y]$

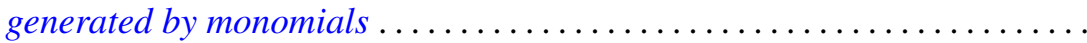

Joseph Barback and Thomas Graham McLaughlin, On the intersection of

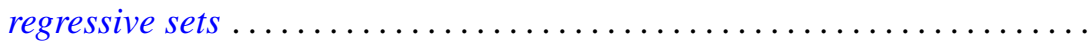

Murray Bell, John Norman Ginsburg and R. Grant Woods, Cardinal inequalities for topological spaces involving the weak Lindelof

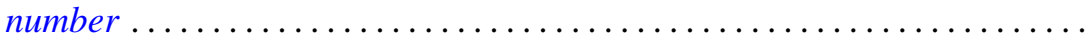

Laurence Richard Boxer, The space of ANRs of a closed surface ............

Zvonko Cerin, Homotopy properties of locally compact spaces at

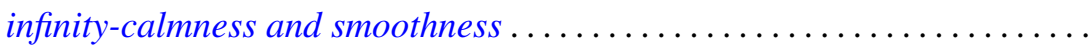

Isidor Fleischer and Ivo G. Rosenberg, The Galois connection between partial functions and relations..................................

John R. Giles, David Allan Gregory and Brailey Sims, Geometrical implications of upper semi-continuity of the duality mapping on a Banach

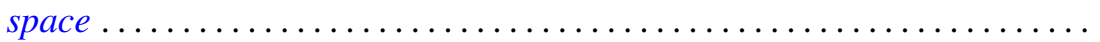

Troy Lee Hicks, Fixed-point theorems in locally convex spaces ............ Hugo Junghenn, Almost periodic functions on semidirect products of transformation semigroups ........................

Victor Kaftal, On the theory of compact operators in von Neumann algebras. II . . . .

Haynes Miller, A spectral sequence for the homology of an infinite

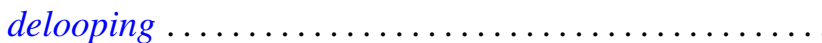

Sanford S. Miller, Petru T. Mocanu and Maxwell O. Reade, Starlike integral operators...

Stanley Stephen Page, Regular FPF rings ...............

Ghan Shyam Pandey, Multipliers for C, 1 summability of Fourier series ...

Shigeo Segawa, Bounded analytic functions on unbounded covering surfaces...

Steven Eugene Shreve, Probability measures and the C-sets of

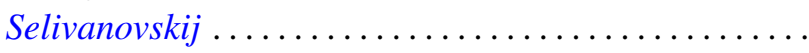

Tor Skjelbred, Combinatorial geometry and actions of compact Lie groups....

Alan Sloan, A note on exponentials of distributions.

Colin Eric Sutherland, Type analysis of the regular representation of a nonunimodular group.

Mark Phillip Thomas, Algebra homomorphisms and the functional

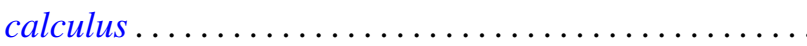

Sergio Eduardo Zarantonello, A representation of $H^{p}$-functions with

$0<p<\infty$. 